\title{
Conceptual Framework of Social Determinants of Health of City Development Project
}

\author{
Shojaei $\mathbf{P}^{1 *}$ and Karimlou $\mathbf{M}^{2}$ \\ ${ }^{1}$ Social Determinants of Health Research Center, Tehran \\ Medical Science Branch, Islamic Azad University, Iran \\ ${ }^{2}$ Social Determinant of Health Research Center, \\ University of Social Welfare \& Rehabilitation Sciences, \\ Iran \\ *Corresponding author: Shojaei P, Social \\ Determinants of Health Research Center, Tehran Medical \\ Science Branch, Islamic Azad University, Iran
}

Received: July 11, 2017; Accepted: August 23, 2017;

Published: August 30, 2017

\begin{abstract}
Potential health advantages of green spaces exposure include the opportunity for activities within the space and psychological advantages of viewing and interacting with nature. We conducted interviews and focus groups with discussion and 35 individual interviews. Interviews and focus groups were conducted to determine the effect of urban man- made lakes on intermediary determinants of health. 28 social determinants of health including "structural" and "intermediary" determinants were extracted out. Thus, two "structural" and "intermediary" groups were formed, and 14 sub-groups were determined in each category. Data analysis matrix was the conceptual frame work of social determinants of health commission; its sub-groups and thus mediating determinant categories as well as their sub-sets were created accordingly. In addition, some extra sub-sets including environment, air quality, weather changes, noise pollution, pathogenesis, quality of life, social and physical development of children, unintentional injuries and aesthetic were extracted beyond the matrix factors, which were placed in intermediary determinant categories based on their thematic content. Quality and type of the urban man-made lake could have a significant and sustained impact on community's health and well-being. Therefore, in order to boost the efficiency of any ongoing projects in the community, their impacts on social health and welfare should be taken into the consideration.
\end{abstract}

Keywords: Man-made lakes; Intermediary determinants of health; Content analysis; Qualitative study

\section{Introduction}

In 2001 the United Nations estimated an increase of $75 \%$ in the level of urbanization in Europe compared to 2000, and also an increase of almost $80 \%$ by 2015 . Urban growth by changing cities and the surrounding countryside creates many problems for the preservation of urban green spaces, and consequently for human health and well-being [1]. The relation between environmental conditions and human health both have been approved by public health practitioners and urban planners. Today, the impact of the built environment on health and well-being is taken into the consideration both in health professional researches and the public. Recent challenges about levels of physical activity, obesity, asthma, mental illness and increasing environmental inequality have increased the importance of the health than before. Now it is time that the authorities of urban planning take action by interlinking both fields to begin a more health-oriented approaches [2]. The concept of a public health observatory in urban settings has been developed to address the barriers imposed by the complex network of health determinants on urban settings [3]. Health is associated with social determinants especially in cities, for more than 150 years a large and continually expanding body of research has shown that the way in which cities are planned and managed can cause a significant difference in the health of residents [4]. There is a lack of evidence and methods for quantifying the beneficial role of the environment to support and improve human health and well-being. Essential knowledge gaps stay in assessing and indicating the multiple functions of green space infrastructure [5].
Urban green space is emphasized in policy documents worldwide and is considered the main aspect of the sustainable city [6]. According to definition of green space Scotland (2008), the term green space can be applied to any vegetated land or surface water body within or adjoining the urban areas, including natural and semi-natural habitats; countryside immediately adjoining a town which people can access green corridors paths, rivers and canals, amenity grassland, parks and gardens, outdoor sports facilities and playing fields [7]. Therefore, the man-made lakes are green space and also have the effects of green space on heath. There are many advantages available to individuals, organizations, and communities from a green environment. Most recorded benefits of living, working, or playing in a green environment have been obtained by individuals. Prospects of vegetation and water (e.g., rivers or lakes) have been shown to reduce stress, enhance healing, and reduce driving failure [8-9]. Despite a wide range of studies on health effects of urban development projects, a few studies have been carried out on urban man-made lakes and its surrounding green spaces. Based on what Santa found out in the study namely "assessment of health effects of walk able urban green spaces," these spaces affect public health both directly and indirectly and are going to have a correlation with health status of local residence as well as environmental quality improvement [10]. According to the results of Irvine and et al (2013), the personal benefits of contact with urban nature comprise the increase of cognitive performance, social interactions, stress relief and also reduction of mental fatigue [11]. Indeed, access to the greenery has been considered important in urban planning, historically, indicated 
by examples such as widespread creation of public parks in the UK during the Victorian era [12]. Therefore, placing health issues in urban projects and plans are essential. Designing and building manmade lake in developing counties usually follow many dangers. Stakeholders need to sit around a table and have active participations in order to utilize the full potential of the lake and water sources projects, improve and maintain them. Therefore, it necessitates the collaboration of not only engineers but also other health sector experts such as biologists, sociologists, and economists due to the important role of each in planning and implementing developmental projects [13]. One of these under-construction projects in Iran was constructing the biggest man-made lake by volume 10 Million Cubic Meter (MCM), by the average depth of 10 meters (m.) and by the area 225 hectares (ha) in North West of Tehran in district 22. Kan River supplied approximately $80 \%$ of lake water and the remainder comes from the run-off of intermediate and surface area of the region [14]. History of construction of the lake project dated back to the development of the first comprehensive plan of Tehran city in 1986 which was predicted to build a lake in west Tehran but due to technical and budget restrictions its construction has been remained dormant for years. Finally, in the underlying studies, since 1382-1389, detailed studies were done at different times by the consultant and ambiguities survey was completed. Catchment area of operations on October 2010, and coastal zones operations on July 2012 by the supervision of Sabir Company according to study and design of Tunnel Pars engineering company (Eshtuky Pars Company) were began. On May $15^{\text {th }} 2013$, the first phase of the project named Persian Gulf Martyrs was inaugurated [15]. This lake has three islands along with entertainment, sports, games, and green spaces that are created with the aim of providing places for tourist absorption, increasing recreational aspects of area, and escalating happiness spirit among population. Although lack of proper consideration for environmental and health issues in the design, implementation and operation of these places could cause severe health problems. According to what mentioned above, a study namely "Health impact assessment of man-made lake in city development strategy on health and social determinants of health" was implemented, and this article has been extracted from it with the intention of characterizing intermediary determinants of health in the current study.

\section{Materials and Methods}

\section{Inclusion criteria}

1. Experts that were employed in city development planning (individuals that have activity in deputy of city development strategy and planning of Municipal District 22) and area related to health determinants (such as house, education, environment, security, transport, etc).

2. The council of region 22 as people representative

3. Have at least one year of work in the field are former self

4. Having academic education in urban project and health

5. Consent to participate in individual interviews or in focus group discussion

\section{Exclusion criteria}

1. Not wanting to participate in the meetings of the study

\section{Participant recruitment}

The focus groups runs counter to critical characteristics that important for holding it such as Homogeneity of participants, An acceptable environment and Limit on the number of people.

All Experts that were employed in city development planning approached and participated in this study. Individual interviews were carried out on 35 informants in three groups: 1- people who live in the district 22 of Tehran, 2-Members who were involved in the manmade lake project from the municipal district 22 with the following characteristics: educated individuals with at least BA degree, experts in urban development, water sources, environment, urban planning, geography, civil engineering; and 3- To avoid information bias, members from outside the municipal district 22, experts in the field of health determinants and environment, members of NGOs and UNDP with at least a bachelor's degree, were included. Individual interview lasted for 50 minutes. The target group for Focus Group Discussions (FGDs) consisted of 2 expert groups that participated in individual interviews (second and third group). First FGD was held with members who were involved in the man-made lake project from the municipal district 22 with the following characteristics: educated individuals with at least BA degree, experts in urban development, water sources, environment, urban planning, geography, civil engineering; and second FGD with members from outside the municipal district 22, experts in the field of health determinants and environment, members of NGOs and UNDP with at least a bachelor's degree .Numbers of individuals in each focus group was 12 people and lasted for 90 minutes. Informants were selected using purposive sampling and data gathering process was continued until data saturation.

\section{Interviews and Focus Groups}

This qualitative step was conducted with a content analysis method. Data were driven from individual interviews as well as Focus Group Discussions (FGDs) from September to March 2013, respectively. In the present study, purposive sampling was taken and it has been continued till data saturation and new ideas and insights were driven. Interviews (in-person) and focus groups (inperson) with consenting participants were conducted. Discussion was semi structured and conducted with the aim of creating a relaxed and comfortable environment for participants. A first qualitative researcher managed the individual interviews and run the focus groups with assistance of a second researcher who recorded field notes and also asked questions. Focus group discussions and interviews were recorded in their fully and transcribed verbatim. To ensure confidentiality and privacy of participant were used fake names. Focus group discussion guiding questionnaires and in-depth individual interviews were used to document the data. These procedures were developed based on the research team's viewpoints and experts who were familiar with urban development's and health issues as well as library sources and objectives of the study. These questionnaires dealt with concepts regarding various health dimensions of artificial lakes construction. Validity of questionnaires was certified through a pilot study, and needed content, succession, and timing reforms were used after this process. We arranged sessions with municipality to make them aware of the study and asked for any permission required. In addition, informants were clarified about the whole research, from 
its objectives to the methods and confidentiality of the data, and all agreed to take part voluntarily. Main investigator managed the whole interviews. FGD was held in the office of surrogate of mayor with all informants agreed on. We started from general and comprehensive questions in the individual interviews and FGDs, and it progressed to detailed questions by the time. Recording and writing the interviews and FGDs were done in the papers word-by-word. We used Graneheim approach for data analysis [16]. The transcribed documents were handled for their meaning units, and finally were coded. Next, codes based on the meaning units represented by informants and their similarities and discrepancies were extracted and grouped. Having a list of usual social determinants and main categories, data analysis were conducted using content analysis matrix [17] and then, new classes were extracted as analysis continued and they were put in the body of the total data analysis. In order to increase reliability, all codes and themes were checked mutually by research team and at the end of each interview a summary of it was presented to the interviewees. To objectivity of the data, codes by two researchers were used and codes and categories were compared. The methods for obtaining the trustworthiness of the findings, included combining the data collected through the individuals' interviews and focus group discussions, Long-term relationship with the participants and subject of the study, extensive research report writing, reviews by participants and observers. In order to observe the ethics of the research, the following points were adhered to; receiving written and informed consent, stated objectives of the study, permission to record the data, maintaining the anonymity of the participants, the right to withdraw from the study, putting the results of the study to participants, and obtaining approval of the ethics committee of the university.

\section{Results}

This study was conducted in municipality of district 22 of Tehran, in 2012. Participants had a mean age of 30 years old and their education varied from B.A to Ph.D. Based on the list of codes, an overall conceptual framework for the effects of an urban manmade lake and its multiple spaces on intermediary determinates of health was developed, (Figure 1) indicated the conceptual framework. conceptual framework includes Multiple spaces of manmade lakes consist of: playing spaces, Recreational -health spaces \& areas, Reception and residency temporary space, Special spaces, Sport spaces, Green spaces that any of this spaces have different facilities .These spaces have multi-function for people in region 22 and all of Tehran. Then, these functions affect determinants of health and finally effects on the health and wellbeing of individuals and society.

Many participants (60\%) stated most positive impact of manmade lake on Air Quality and Physical Activity, Quality of Life and negative impact on Environmental Health and Pathogenesis. Younger participants (20\%) imply that this lake have positive and negative impact on Nutrition, Unhealthy Behavior and Social Capital. 15\% of participants declared other impact of this lake is Mental Health, Aesthetic and Noise Pollution. According to statement $\mathrm{f}$ participants (5\%) this lake could have impacts on Physical and Social Development of Children, Unintentional Injuries and Weather Changes.

We considered section of the intermediary determinants of health in conceptual framework of "social determinants of health" commission alongside their sub-sets as data analysis matrix [18]. Moreover, some other sub-categories comprising weather changes, environment health, noise pollution, air quality, pathogenesis, quality of life, physical and social development of children, unintentional injuries and aesthetic were extracted as meta-matrix factors, which were placed in intermediary determinants categories based on thematic content. Overally 14 sub categories extracted (Physical and Social Development of Children, Physical Activity, Quality of Life, Nutrition, Unhealthy Behavior, Unintentional Injuries, Pathogenesis, Air Quality, Mental Health, Aesthetic, Social Capital, Weather Changes, Noise Pollution, Environmental Health). Intermediary determinants stratum referred to factors participated in implementation of structural determinants. This stratum consists of behavioral and biological factors, material circumstances, and psycho-social factors. Sub-categories of environment, weather changes, quality of air and noise pollution were placed in material circumstances matrix. This matrix comprises determinants related to the physical environment, such as housing (relating to both the lodging itself and its location), consumption potential, i.e. the fiscal means to buy healthy nutrition, warm clothes, etc., and the physical working and district surroundings. Based on their quality, these conditions both offer resources for health and hold health hazards as well. According to the European Environment Agency (2013), quality of air and water alongside noise pollution in living and working conditions are as part of material circumstances [5], which these subcategories were placed in the matrix.

\section{Air quality}

The most positive effect of this lake, based on participants' view, was its effect on filtering of air pollution. This lake with greenspace surrounding of make humidity in the region, which it has significant impacts on people's health. An environmental expert stated that, "construction of man made in metropolitan areas absorbs tourists, bedsides increasing the green space per capita and filtering the air."

\section{Weather exchanges}

According to informant's opinion, green spaces of this lake increase biodiversity and providing a soak area for flooding and other climate change impacts. "We can maintain natural ecosystem via understanding the mutual effects of lake and environment and their changes, and applying them in improving weather conditions and natural environment as well as decreasing the range of temperature variations in the region."

\section{Noise pollution}

This lake with different playing space specially Children's play areas, made noise for tower residents in surrounding of this lake and for all of the region 22 in holidays. "Noise and bustle of people have negative influences on individuals' mental health and cause sleepless especially at night and holidays".

\section{Environment health}

The changing this region to a touristy place due to building the lake and the plurality of visitors which made the role of environmental management important. This lake with many spaces increase in hazards and risks related to greenspace and then cause contamination of environment. Meanwhile, one of the most problematic issues was related to water circulation properly. An expert stated, "ecologic 


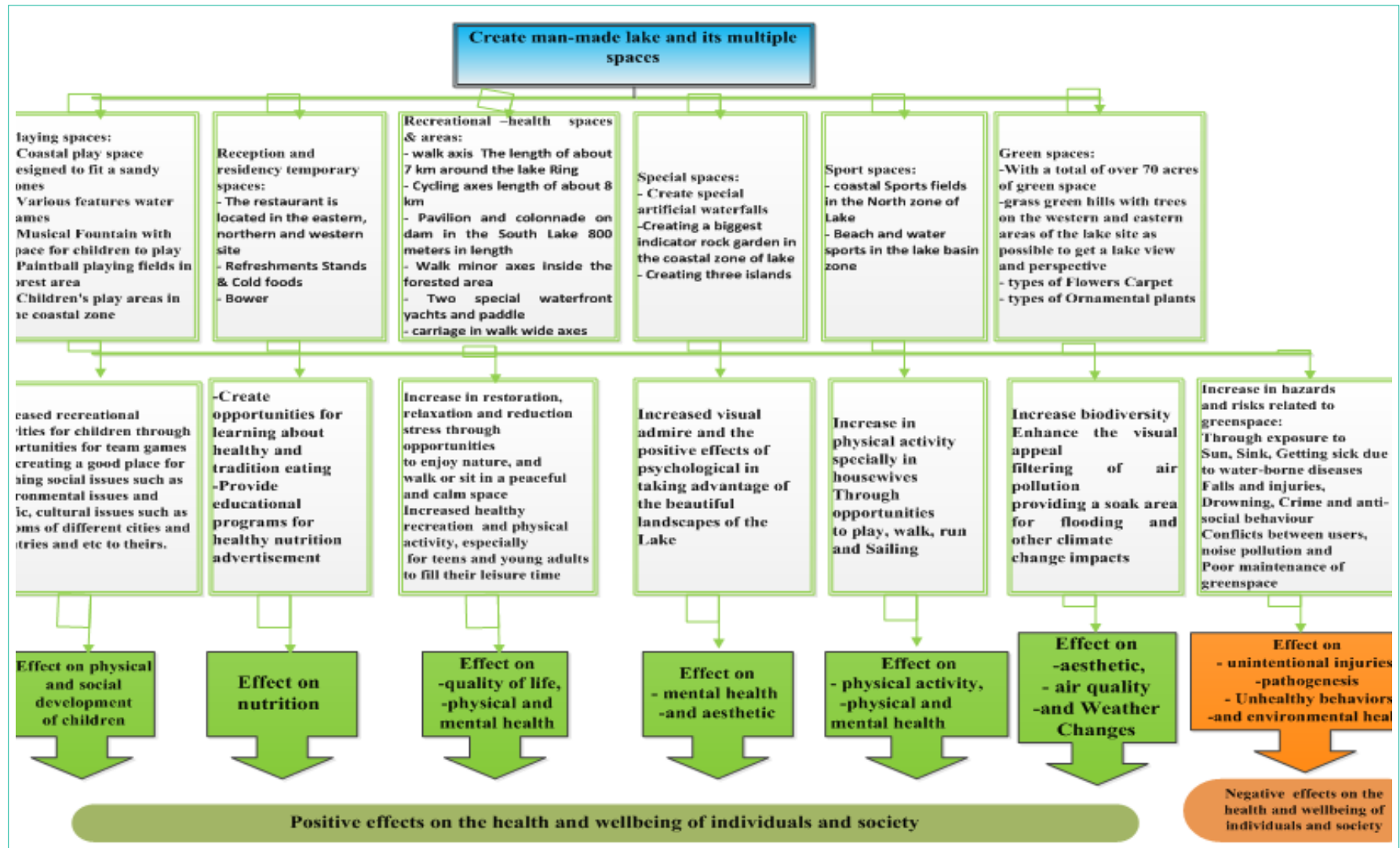

Figure 1: The conceptual framework of effects of man-made lake and its multiple spaces on intermediary determinants of health.

reserves as well as forest and herbal covers of the region (Chitgar park) will be reduced because of the increased volume of traffic, visitors, and pollution and problems resulting of their".

The following sub-categories of unhealthy behaviors, nutrition and physical activity that are considered as lifestyle [19] and subcategories of quality of life and unintentional injuries, pathogenesis as well as physical and social development of children were put in "behaviors and biological factor" matrix. This matrix consisted of smoking, alcohol use, diet and lack of physical workout which could be either health keeping and enhancing (such as exercise) or health injuring (cigarette smoking and fatness). Among biological factors, we were involved in genetics factors as well as age, and sex distribution.

\section{Unhealthy behaviors}

Participants declared that due to specific and forestry spaces around the lake, they are concerned about emergence of some unhealthy and anti-cultural and social behaviors such as Crime and Conflicts between users, especially among young boys and girls."In this spaces, increase crime and Unhealthy behaviors if don't have good management".

\section{Nutrition}

These spaces Create opportunities for learning about healthy and tradition eating. "Educational programs for healthy nutrition advertisement are very important". In some cases, selling of harmful eating and fast food in restaurant of this lake that encourage unhealthy nutrition, have negative impact on health.

\section{Physical activity}

Construction of the lake and creation of suitable places for sports, water games, and walking environments as well as bicycle lane around the lake increased level of physical activity and reduced mental problems. One participant cited "increasing levels of physical activity improves physical and mental health, particularly among housewives, and decrease osteoporosis among them".

\section{Quality of life}

The most benefits of construction of this lake and its spaces is increase in restoration, relaxation and reduction stress through opportunities to enjoy nature, and walk or sit in a peaceful and calm space, increased healthy recreation and physical activity, especially for teens and young adults to fill their leisure time. From some others' view, development of tourism in the region 22 would cause the absorption of income, speed up the circulation of money, raise employment level and finally it would increase quality of life of the inhabitants.

\section{Pathogenesis}

Getting sick due to water-borne diseases as a result of the lake construction. "It is possible that, some diseases emerge because the lake is a natural ecosystem, poor hygiene of visitors and tourists can also bring in some contagious diseases with themselves."

\section{Unintentional injuries}

Construction of the lake and its multiple spaces, increase hazards and risks related to greenspace especially for children that cause 
physical damages. In one informant's view, "there are likely to sink into the lake for residents, park visitors, mainly children and youth."

\section{Physical and social development of children}

Physical and social development of children sub-category was situated in intermediary determinants category [20]. Create manmade lake and its multiple spaces increased recreational activities for children through opportunities for team games and creating a good place for teaching social issues such as environmental issues and traffic, cultural issues such as customs of different cities and countries and etc to theirs. An expert stated "here is a good chance for education of various social issues such as traffic issues, environmental and cultural subjects like cities and different countries traditions etc. to children in order to help them training together along with fun and recreation".

Mental health and aesthetic sub-categories were placed in psychological factors matrix. This matrix comprises psychosocial stress makers (for instance, adverse life events and job pressures), stressful living situations (e.g. high debt), and absence of social support, managing styles, etc.

\section{Mental health}

One of the very important issues mentioned by informants was mental health. Increased visual admire and the positive effects of psychological in taking advantage of the beautiful landscapes of the Lake A participant stated "health recreations and interesting aquatic games as well as social interactions among individuals help them evacuation their mind from confusion and cause passion and joy."

\section{Aesthetic}

This lake could play an important role in creation visual admire and beautiful landscapes. Grass green hills with trees on the western and eastern areas of the lake site as possible to get a lake view and perspective. According to experts, "Special spaces of the lake such as Create special artificial waterfalls, islands and types of flowers give beautiful landscape to region 22". Based on the list of codes, an overall conceptual framework for the effects of an urban man-made lake and its multiple spaces on intermediary determinates of health was developed, (Figure 1) indicated the conceptual framework.

\section{Discussion}

Results of the present study indicated that based on the conceptual framework of social determinants of health commission, lake construction affected on intermediary determinants of health as well as their sub-categories. Similar studies have also referred on these intermediary determinants. Morris expressed some of the environmental benefits of natural open and green spaces such as filtering air pollution, stabilization of ground surfaces, the seize of rainfall which decreases flooding, the creation of visual and sound barricades, the provision of temporary cover for run-down sites, promoting the sustainability of wildlife habitats, emotional wellbeing, reduction of stress in the certain circumstances, improvement of health, increase of physical activity and quality of life, enhancement of the mass communication and interpersonal skills, improvement of spiritual, sensory, and aesthetic awareness, and the ability to assert personal control and increase of sensitivity to one's own well-being [21]. Lee and Maheswaran in their study namely "the health benefits of urban green spaces" stated that there existed weak evidence to support the relationship between physical and mental health with urban green spaces, whereas access to quality of green spaces would affect physical activities of people, and in fact, the age, gender, ethnicity, and safety perception of people were important in this regard, as well [22]. According to the results, Persian Gulf Martyrs Lake with surrounding green spaces as new ecological zones helped to soften the air in the area. Since the specific heat capacity of water is high, the lake water can store large amounts of heat; this sometimes causes a decrease in the amplitude of temperature changes. South Carolina Institute of Medicine and Public Health (IMPH) evaluated the health effects of parks, forest paths, and green spaces plans in west part of Greenville, and found out that one of the important determinants associated with these spaces was the quality of air [23]. Faculty of Public Health of London reported enhancement of welfare and mental health for all, increased physical activity, reduced violence, and anti-social behaviors, decreased health disparities, declined mortality and cardiovascular diseases, improvement of air quality, solving noise pollution, and fiscal profits as health determinants associated with green spaces [24]. Heinze reported that healthy and properly maintained green space supplied essential benefits to the environment in terms of water and air refinement and temperature changes [25].

Urban green space provides many direct environmental benefits. Urban trees for example help improve the air quality by capturing air pollution [26]. McPherson, Graves and colleagues referred to these findings in their researches as well [27]. The lake and surrounding green spaces with recreational areas and sports fields for hiking, rafting, and etc., provides the opportunity for individuals exercise and physical activity and decrease obesity and its related diseases. According to findings of urban heart study in 2012 in Tehran, the percentage of overweight and obese men and women was high in one of the neighborhoods near the lake in district 22 of Tehran that the lake might have a positive effect on reducing those. Adjustment of the built environment to make green space, increase opportunities for beneficial 'green exercise' such as walking [28]. Godbey and colleagues stated that there are possible leisure-time physical activities in a variety of community environments, such as local parks [29]. Several studies supported this opinion that 'the built environment can facilitate or constrain physical activity [30]. In a European study of eight cities, people living in areas with high levels of greenery were three times more likely to be physically active and the chance of being overweight and obese was about $40 \%$ lower than in people living in similar areas with low levels of greenery. However, people living in the areas with high levels of anti-social activities were less likely to be physically active and more likely to be overweight or obese [31]. In a systematic review of 50 quantitative studies examined relationships between green space access and physical activity, 20 reported positive associations (higher physical activity with increased green space access), 15 were weak or mixed, 2 were negative and 13 found no evidence of any association [32]. Various attributes of the built environment (e.g., population density, street connectivity, land use mix) have been associated with rates of physical activity at the neighborhood level [33]. In a study about contribution of public parks to physical activity, easy access to larger and more attractive public open space was a significant factor of people attaining high 
levels of walking in these places [34]. Positive associations with increased levels of physical activity were reported for the amount of urban green spaces close to home [35] Schipperijn [36], Foster [37], Giles-Corti and colleagues [38], Pretty and colleagues [39] acknowledged the relationship between green space and physical activity as well. As the results were expressed, lake construction reduced anxiety and depression and increased mental health. Contact with green space in the environment has been connected with mental health advantages, but the mechanism supported this association was not clear [40]. The evidence was specifically strong for positive associations [41]. Experimental research has also begun to examine the effect of natural versus urban environments on benefits of running [42]. Close green view from apartment buildings have been shown to enhance residents' effectiveness in facing their serious life problems and to lessen intra-family destructive behavior by reducing mental fatigue. These surveys used statistical mediator variable analysis to show the association between green agents and psychological variables [43]. Community advantages might help particular individuals, but determining that, who gets which advantages particularly, when designing or assembling support for a program, was important. Community benefits when individual benefits are more likely could have negative effects on a program [44]. Other researchers such as Schipperijn [36], Nielsen \& Hansen [45], Kaplan [46], Renema and colleagues [47] and Rossman \& Ulehla [48] confirmed the relationship between psychology variables and these spaces in their articles. According to results of the study, lake with a special play area for children which also used for teaching different issues such as traffic training, environmental issues, and etc. would enhance physical development of children. Taylor and et al in a study with the title "Growing up in the inner city green spaces as places to grow" indicated that green places are better places for living and playing to children. Playing in places with trees and vegetation could strengthen children's development of skills and cognitive abilities [49]. Research on the determinants of healthy child development indicated that studies should comprise a mix of social and environmental agents income, education, health and everyday environments in all levels of society [50]. Physical activity researchers, on the other hand, have not importantly showed how the wider social and physical environment influences children's play and mobility. Active behaviors should be encouraged with city planning and infrastructure by creating secure and accessible urban environments [51]. Veugelers and et al., stated that Playgrounds, parks and other recreational facilities engaged children living nearby these places in more physical activities and were less likely to be obese [52]. According to statements of participants in results of the study the improvement of lifestyle and specially the increase of mental health in housewives would enhance quality of life in this environment. According to Westphal research, urban and community forestry played a key role in increasing quality of life. This role could be promoted by careful thought and planning concerning the innumerable potential social benefits available via urban and community greening programs. Through enhanced experiences of green views and programs strong active engagement in urban greening, urban and community foresters could be a very real part of the solution to difficult social problems faced by large or small communities [44]. Burgess and et al determined in their project an extent need for variety of both natural settings and social facilities within local areas and drew attention to the potential of urban green spaces to improve the quality of life of all citizens [53]. The results showed that if these areas are not managed well, they will really make the community vulnerable due to the existence of false jobs which influence on the increase of unhealthy behaviours. On the other hand, by entertaining the youth with a variety of educational and recreational programs unhealthy behaviors would decrease. Coutts and et al., indicated that the accessibility to green space have an effect on health behaviours supported by an ecological model of health. An ecological model includes multiple levels of effects on health and health behaviors [54]. According to results, another effect of man-made lake was its outlooks and aesthetic aspects. Participants expressed that existence of water is visually attractive. Urban designers and planners are aware of the strong effects of aquatic bodies on quality of life of all citizens, even small and narrow like lake. These effects include internal and intrinsic aesthetic features, and have recreational and educational utilities, which light urban area up [55]. Outdoor recreation and in particular, walking in green spaces is a multi-sensual and stimulating experience which frees the mind and products reflexivity, philosophical and intellectual thought, aesthetic contemplation and opens up a more 'natural' self [21]. Research seeking to recognize humans' positive relationships with nature has gradually expanded over the last 20 years especially in the area of aesthetic priorities for varying views [56]. Today, the function of worshipping God has declined in public green space, while aesthetic and recreational perspective are still dominant values related to urban green space construction, especially in intensive built up areas. In ancient urban planning practice, aesthetic and religious meanings in Shan-shui culture, the mountains and water for their functional and technical aspects were also used. However, cultural values and aesthetic appreciation of landscape should institutionalize in the planning and management of landscapes [57]. Liu in one research showed that the cultural and aesthetic qualifications, rather than natural aspects, are still dominant in contemporary urban green space construction, and that urban green area development tends to be close to the art rather than modern ecology [58]. In general, green spaces play important roles in balancing urban economic sectors, urban spatial structure and improving city images internationally encounter the local growing demand for recreation, leisure, quality of life, public health and the like [57]. The preservation and expansion of green spaces such as man-made lakes and green space surrounding could be framed as a health benefit to individuals, which may supply a flavor rationale for environmentally sound policy decisions. The need for adequate level of close green spaces is an important message for landscape and urban planners when designing new residential growth, repairing existing urban infrastructure or consulting on land use preferences [32]. From a social perspective, the most important consideration about lakes should begin with their stakeholders (people who spend their free times by the lakes, those who perform role in creating and management of man-made lakes, those who use water of these lakes). According to Nakagamis study, difficulties of proper lake management come from its stakeholders [59]. All organizations and stakeholders should be aware of merits and demerits of constructing lakes and management of their water, and all contracts and obligations should be arranged in advance between stakeholders [60]. Yet for the number of reasons the high level of urban pressures, lack of integrated planning and management, and 
restricted special knowledge of urban forests and trees, the full potential of urban green spaces is often not met [21]. From the perspective of city planners or green space managers, focusing on the possible changes in the physical environment seems obvious. However, when making changes in the physical environment, it is important to realize that each person has different preferences and needs. Raymore (2002) mentions that any possible environmental constraint or facilitator must be perceived as such before it become a constraint or facilitator in reality. Environmental factors constraining the use for one person might stimulate use for another person and vice versa. Therefore, it is essential to understand the individual factors that influence the use and perception of a specific urban green space before planning any physical changes in this green space [61]. Budgets for manmade lakes management are determined by municipal politicians, and the strong maintenance focus seems to have lead to a relatively low interest from politicians in urban green space. For that reason, it is important for manmade lakes managers to highlight which benefits for society can contribute to from their. One way of doing this is by strategic cooperation with other departments, e.g. the health or education department. This way of thinking is relatively new in many cities, but looks promising. However, tools to support this type of strategic green space management are not readily available. Data gathered in this field also had a strong maintenance focus and were often less suitable to support the making of strategic decisions. In the other steps of this study we conduct quantitative study for prioritized and weighing the determinants by calculating AHP, and using Technique for Order Preference by Similarity to Ideal Solution (TOPSIS) method for decide and ranking alternatives.

\section{Acknowledgement}

This research is derived from the $\mathrm{PhD}$ thesis in specialized research social determinant of health approved by Research Council Session in University of Social Welfare and Rehabilitation Sciences and the meeting of Ethics Committee of that university. We appreciate the Cooperation by honorable research deputy of university and honorable Municipality of district 22 of Tehran.

\section{References}

1. United Nations, World Urbanisation Prospects: The 1999 Revision., in Urban Observatory and Statistics Unit. New York.

2. Verbeek $T$, Boelens $L$. Urban planning and public health: revaluing a legacy from the past. in AESOPIACSP $5^{\text {th }}$ joint congress 2013: Planning for resilient cities and regions (27 $7^{\text {th }}$ International conference of the Association of European Schools of Planning; $53^{\text {rd }}$ Annual conference of the Association of Collegiate Schools of Planning). 2013: Association of European Schools of Planning (AESOP); Association of Collegiate Schools of Planning (ACSP).

3. Caiaffa W. Developing a Conceptual Framework of Urban Health Observatories toward Integrating Research and Evidence into Urban Policy for Health and Health Equity. Journal of Urban Health. 2013; 1-16.

4. Rydin Y. Shaping cities for health: complexity and the planning of urban environments in the $21^{\text {st }}$ century. Lancet. 2012; 379: 2079.

5. Environment and human health. Joint EEA-JRC report. 2013, European Environment Agency, Publications Office of the European Union: Denmark.

6. Bengston DN, Fletcher JO, Nelson KC. Public policies for managing urban growth and protecting open space: policy instruments and lessons learned in the United States. Landscape and urban planning. 2004; 69: 271-286.

7. Greenspace Scotland, Health Impact Assessment of Greenspace. 2008

8. Ulrich RS. View through a window may influence recovery from surgery
Science. 1984; 224: 420-421.

9. Parsons R. The view from the road: implications for stress recovery and immunization. Journal of environmental psychology. 1998; 18: 113-140.

10. Santana P, Santos R, Costa C. Walkable Urban Green Spaces: Health Impact Assessment in Amadora, Portugal'. REAL CORP 2009: CITIES 3.0Smart, Sustainable, Integrative Strategies, Concepts and Technologies for Planning the Urban Future. 2009; 579-585.

11. Irvine $\mathrm{KN}$. Understanding urban green space as a health resource: A qualitative comparison of visit motivation and derived effects among park users in Sheffield, UK. International journal of environmental research and public health. 2013. 10: 417-442.

12. Walker SE, Duffield BS. Urban parks and open spaces-an overview. Landscape Research. 1983; 8: 2-12.

13. Araoye P. Man-made lakes, ecological studies and conservation needs in Nigeria. Revista de biología tropical. 2002; 50: 857-864.

14. Nouri JH, Rahimipour, Nezakati R. Simulation of Thermal Stratification in Urban Man-made Lakes. American Journal of Applied Sciences. 2004; 1 : 309.

15. Chitgar manmade lake. Municipality of District 22: Tehran. 2013.

16. Graneheim UH, Lundman B. Qualitative content analysis in nursing research: concepts, procedures and measures to achieve trustworthiness. Nurse education today. 2004; 24: 105-112.

17. Averill JB. Matrix analysis as a complementary analytic strategy in qualitative inquiry. Qualitative Health Research. 2002; 12: 855-866.

18. Solar O, Irwin A. A conceptual framework for action on the social determinants of health. 2010

19. Committee $\mathrm{NH}$. The social, cultural and economic determinants of health in New Zealand: action to improve health. Wellington: National Health Committee. 1998.

20. Organization towards a conceptual framework for analysis and action on social determinants of health. Secretariat Commission on Social Determinants of Health. WHO. Geneva, Suiza. 2005; 22-36.

21. Morris N. Health, well-being and open space. Literature Review. OPEN space: the research centre for inclusive access to outdoor environments. Edinburgh College of Art and Heriot-Watt University, Edinburgh. 2003.

22. Lee A, Maheswaran $R$. The health benefits of urban green spaces: a review of the evidence. Journal of public health. 2011; 33: 212-222.

23. South Carolina Institute of Medicine and Public Health (IMPH). A Health Impact Assessment (HIA) of Park, Trail, and Green Space Planning in the West Side of Greenville, South Carolina. South Carolina Institute of Medicine and Public Health (IMPH). 2013.

24. Faculty of Public Health. Great Outdoors: How Our Natural Health Service Uses Green Space to Improve Wellbeing. 2010.

25. Heinze J. Benefits of Green Space - Recent Research. A nonprofit Research Foundation Specializing in Health and Environmental L Science. 2013; 5.

26. Nowak DJ, Crane DE, Stevens JC. Air pollution removal by urban trees and shrubs in the United States. Urban forestry \& urban greening. 2006; 4: 115123.

27. McPherson EG. Atmospheric carbon dioxide reduction by Sacramento's urban forest. Journal of Arboriculture. 1998; 24: 215-223.

28. Pretty J. Green exercise: complementary roles of nature, exercise and diet in physical and emotional well-being and implications for public health policy. University of Essex, CES Occasional Paper. 2003.

29. Godbey GC. The role of parks and recreation in promoting physical activity and health. Franklin County Healthier Communities through Active Living Summit, Kauffman Station PA. 2003

30. Bedimo-Rung AL, Mowen AJ, Cohen DA. The significance of parks to physical activity and public health: a conceptual model. American journal of preventive medicine. 2005; 28: 159-168. 
31. Ellaway AS, Macintyre, X. Bonnefoy, Graffiti, greenery, and obesity in adults: secondary analysis of European crosses sectional survey. BMJ: British Medical Journal. 2005; 331: 611.

32. Lachowycz K. What can global positioning systems tell us about the contribution of different types of urban greenspace to children's physical activity? Health \& Place. 2012; 18: 586-594.

33. Hankey SJD, Marshall, Brauer M. Health impacts of the built environment: within-urban variability in physical inactivity, air pollution, and ischemic heart disease mortality. Environmental health perspectives. 2012; 120: 247.

34. Cohen D. Contribution of public parks to physical activity. American Journal Public Health. 2007; 97.

35. Kaczynski AT, Potwarka LR, Saelens BE. Association of park size, distance, and features with physical activity in neighborhood parks. American Journal of Public Health. 2008; 98: 1451.

36. Schipperijn J. Use of urban green space. Forest \& Landscape Research, Denmark, Frederiksberg: Skov \& Landskab, Københavns Universitet. 2010.

37. Foster CM, Hillsdon, Thorogood M. Environmental perceptions and walking in English adults. Journal of epidemiology and community health. 2004; 58: 924-928.

38. Giles-Corti B. Increasing walking: how important is distance to, attractiveness, and size of public open space? American journal of preventive medicine. 2005; 28: 169-176.

39. Pretty J. The mental and physical health outcomes of green exercise International journal of environmental health research. 2005; 15: 319-337.

40. Roe J. Green Space and Stress: Evidence from Cortisol Measures in Deprived Urban Communities. International journal of environmental research and public health. 2013; 10: 4086-4103.

41. Ward Thompson C. More green space is linked to less stress in deprived communities: Evidence from salivary cortisol patterns. Landscape and urban planning. 2012; 105: 221-229

42. Bodin M, Hartig T. Does the outdoor environment matter for psychological restoration gained through running? Psychology of Sport and Exercise. 2003 4: 141-153.

43. Kuo FE, Sullivan WC. Aggression and violence in the inner city effects of environment via mental fatigue. Environment and behavior. 2001; 33: 543571.

44. Westphal LM. Urban greening and social benefits: a study of empowerment outcomes. Journal of Arboriculture. 2003; 29: 137-147.

45. Nielsen TS, Hansen KB. Do green areas affect health? Results from a Danish survey on the use of green areas and health indicators. Health \& place. 2007; 13: $839-850$.

46. Kaplan S. Meditation, restoration, and the management of mental fatigue. Environment and Behavior. 2001; 33: 480-506
47. Renema D. De wensen van Nederlanders ten aanzien van natuur en groen in de leefomgeving (The Wants of the Dutch for Nature and Green in the Living Environment). Wageningen, DLO-Staring Centrum. 1999.

48. Rossman BB, Ulehla ZJ. Psychological Reward Values Associated with Wilderness Use A Functional-Reinforcement Approach. Environment and Behavior. 1977; 9: 41-66.

49. Taylor AF. Growing up in the inner city green spaces as places to grow Environment and behavior. 1998; 30: 3-27.

50. Bonnefoy J. Constructing the evidence base on the social determinants of health: A guide. Measurement and Evidence Knowledge Network (MEKN). 2007.

51. Lopez RP, Hynes HP. Obesity, physical activity, and the urban environment: public health research needs. Environmental Health. 2006; 5: 25.

52. Veugelers P. Neighborhood characteristics in relation to diet, physical activity and overweight of Canadian children. International Journal of Pediatric Obesity, 2008. 3: 152-159.

53. Burgess JCM, Harrison M. Limb, People, parks and the urban green: a study of popular meanings and values for open spaces in the city. Urban studies. 1988; 25: 455-473.

54. Coutts C. County-Level Effects of Green Space Access on Physical Activity. 2013.

55. Zhang FL, Liu JL, Yang ZF. Ecosystem health assessment of urban rivers and lakes for six lakes in Beijing. Acta Ecologica Sinic a. 2005; 25: 3019 3027.

56. Gullone E. The biophilia hypothesis and life in the $21^{\text {st }}$ century: Increasing mental health or increasing pathology? Journal of Happiness Studies. 2000; 1: 293-322.

57. Chen C. Planning urban nature: urban green space planning in post-1949 China: Beijing as a representative case study. A thesis submitted in fulfilment of the requirements for the Degree of Doctor of Philosophy in Landscape Architecture. Lincoln University: New Zealand. 2013.

58. Liu L. Status and prospects for urban green structure planning in China. 2008.

59. Nakagami K. Interest Groups Involved with the use of Water Resources/ Environments. 1991; 19-22.

60. Minnesota Lakes Association. Sustainable lakes planning workbook: a lake management model. 2000, Minnesota: University of Minnesota. Center for Urban Regional Affairs

61. Schipperijn J. Influences on the use of urban green space-A case study in Odense, Denmark. Urban forestry \& urban greening. 2010; 9: 25-32.
Austin J Public Health Epidemiol - Volume 4 Issue 2 - 2017

ISSN : 2381-9014 | www.austinpublishinggroup.com

Shojaei et al. (C) All rights are reserved
Citation: Shojaei P and Karimlou M. Conceptual Framework of Social Determinants of Health of City Development Project. Austin J Public Health Epidemiol. 2017; 4(2): 1060. 